\title{
Pediatric asthma and autism-genomic perspectives
}

\author{
Sunghee $\mathrm{Oh}^{1+}{ }^{1+}$, Hong $\mathrm{Ji}^{2+}$, Drew Barzman ${ }^{3+}$, Ping-l Lin ${ }^{4+}$ and John Hutton ${ }^{5^{*}}$
}

\begin{abstract}
High-throughput technologies, ranging from microarrays to NexGen sequencing of RNA and genomic DNA, have opened new avenues for exploration of the pathobiology of human disease. Comparisons of the architecture of the genome, identification of mutated or modified sequences, and pre-and post- transcriptional regulation of gene expression as disease specific biomarkers are revolutionizing our understanding of the causes of disease and are guiding the development of new therapies. There is enormous heterogeneity in types of genomic variation that occur in human disease. Some are inherited, while others are the result of new somatic or germline mutations or errors in chromosomal replication. In this review, we provide examples of changes that occur in the human genome in two of the most common chronic pediatric disorders, autism and asthma. The incidence and economic burden of both of these disorders are increasing worldwide. Genomic variations have the potential to serve as biomarkers for personalization of therapy and prediction of outcomes.
\end{abstract}

Keywords: Genomic variation, Transcription, Pathobiology, Pediatric disorders, Autism, Asthma

\section{Introduction}

Both autism spectrum disorder (ASD) and asthma are among the most common pediatric chronic diseases worldwide and pose an enormous economic burden on health care delivery systems $[1,2]$. There has been recent progress in identifying underlying genomic changes in these disorders, which will be reviewed here. Unveiling changes in the genome that underlie disease identify new biomarkers that have the potential to predict outcomes of treatment and to identify targets for development of new therapies.

\section{Review}

\section{Copy number variation}

Copy number variants (CNVs) are structural alterations of DNA that increase or decrease the number of copies of one or more sections in a strand of DNA within a chromosome [3]. CNVs have been associated with

\footnotetext{
*Correspondence: john.hutton@cchmc.org

'Sunghee Oh, Hong Ji, Drew Barzman, Ping-I Lin contributed equally to this work

${ }^{5}$ Division of Biomedical Informatics, Department of Pediatrics, Cincinnati Children's Hospital Medical Center, Cincinnati, OH 45229, USA

Full list of author information is available at the end of the article
}

certain diseases, for example autism spectrum disorder (ASD) and schizophrenia. Family and twin studies have strongly suggested that certain genetic variants can substantially influence the risk of ASD and de novo mutations in the form of CNVs contribute to the risk of autism $[4,5]$. Recent deep sequencing studies have generated robust evidence for the link between recurrent rare variants and ASD [6-8]. Vaishnavi et al. found that $11 \%$ of ASD-related copy number variants (CNVs) contained microRNAs (miRNAs) [9]. These CNV-miRNAs formed a regulatory loop with transcription factors and their downstream target genes, and annotation of these target genes indicated their functional involvement in neurodevelopment and synapse [10]. miRNA studies provide mechanistic insights into genetic regulations that may modulate the risk of ASD. These findings exemplify how functional genomic approaches may facilitate the efforts to decipher genetic mechanisms underlying clinical features of ASD and other heritable disorders. However, susceptibility genes for ASD remain elusive because of difficulty in replicating linkage or association findings [11].

The presence of CNV in childhood asthma has only been recently discovered. Rogers et al. showed that CNV

\section{贷 Springer}

(C) 2015 Oh et al. This article is distributed under the terms of the Creative Commons Attribution 4.0 International License (http:// creativecommons.org/licenses/by/4.0/), which permits unrestricted use, distribution, and reproduction in any medium, provided you give appropriate credit to the original author(s) and the source, provide a link to the Creative Commons license, and indicate if changes were made. 
in candidate asthma genes was prevalent in 383 asthmatic trios participating in the Childhood asthma management program (CAMP) [12]. However, the vast majority of identified CNVs were of rare frequency $(<5 \%)$ and were not statistically associated with asthma. $2 \mathrm{CNVs}$ near NOS1 and SERPINA3 were modestly association with asthma and they were unlikely to explain the previously identified associations between SNP and asthma.

\section{Gene fusion}

While gene fusions are well known as a major factor in both initiation and progression of cancers [13], they are rare in both diseases in our study. Copy number variants are known to occur in both ASD and asthma. CNVs can facilitate combining parts of two genes, resulting in a fusion transcript. Holt et al. [14] identified fusion-gene generating CNVs in probands with ASD, however there was no difference in overall frequency of fusion transcripts between patients and normal controls. Ceroni et al. [15] identified a child with both ASD and asthma, who inherited a maternal deletion that resulted in a BST1-CD38 fusion transcript. Whether the fusion transcript causes changes in function that underlies ASD and/or asthma in the child has not yet been studied.

\section{Non-coding RNAs}

Non-coding RNAs, both microRNAs (miRNA) and long noncoding RNAs (lncRNA), play a key role in functional genomics-stability and maintenance of gene expression. For example, they both play a major role in regulating chronic inflammatory diseases such as asthma [16]. Geaghan and Cairns have reviewed evidence that numerous microRNAs (miRNA) play a role in ASD and other psychiatric disorders, characterized by dysregulation of target transcripts [17]. Abnormal large noncoding RNAs significantly contribute to the pathology of autistic brain $[18,19]$.

\section{Mutations in mitochondrial genome}

Mitochondrial dysfunctions occur in several human inherited disorders [20]. Mitochondrial dysfunction is hypothesized to play a role in asthma. Flaquer et al. compared mitochondrial SNPs in 372 asthmatic children and 395 health controls [21]. Different variants were found in asthmatic boys and girls. For boys significant differences were found in the CYB gene; for girls in the NADHdehydrogenase subunits. Post-mortem brain studies have suggested an elevated prevalence of mitochondrial dysfunction in ASD [22].

\section{Epigenetic modification of the genome}

Expression of genes can be turned on or off or modified by factors other than an individual's DNA sequence.
Although all organs of the body contain the same DNA, the pattern of expression of genes differs from organ to organ because of epigenetic factors [23]. The most common modification that influences expression of genes is DNA methylation. Methylation of DNA involves the conversion of cytosine to methylcytosine at a site in DNA. The cytosine nucleotide to be methylated is located next to a guanine nucleotide, i.e. in a CpG dinucleotide, although recent research has found methylated cytosine in other sequence contexts, such as CpA [24]. Genes with highly methylated promoters typically are not well expressed. Changes from normal patterns of DNA methylation of specific genes can cause alterations in gene expression that are associated with disease. Epigenomewide association studies (EWAS) hold promise for the detection of new regulatory mechanisms that may be susceptible to modification by environmental and lifestyle factors affecting disease [25]. Because of the rapid advances in sequencing technology, large numbers of methylated $\mathrm{CpG}$ sites can be identified across the entire genome. Because DNA methylation is tissue-specific, having a mixed cell population makes it hard to link the observed DNA methylation patterns to the disease rather than to changes in cell populations. Investigators must prospectively identify the sources of cells and define appropriate profiling methods.

The role of DNA methylation in pediatric diseases has recently been established. Most of the data are derived from studies of genes the investigators selected because they were thought to be involved in causation of the disease, the candidate gene approach. With the emergence of high-throughput technologies, ranging from microarrays to next-gen sequencing, genome-wide scanning to search for disease-related DNA methylation markers is now possible. The interplay among DNA methylation sites, genetic variation, protein binding sites, and gene expression is a very active field of investigation.

Emergent evidence has shown that epigenetic modifications of DNA, rather than single-locus variation, may account for the heritability of ASD [26-28]. Compared to other psychiatric disorders with variable onsets across the lifespan, ASD, where the onset occurs by the age of two, represents one of the few disorders in which timedependent penetrance is not a primary concern. The high heritability of ASD may also lead to a higher chance of success in mapping the risk genes for this disorder. Prevalence of ASD has a male excess of 4:1 and dysregulation of methylation in brain-expressed genes on the $\mathrm{X}$-chromosome has been speculated to contribute to the development of ASD [29]. Nararajan and colleagues reported that a significant reduction in the expression of the $\mathrm{MeCP} 2$ gene, which encodes methyl CpG binding protein 2, was found in $79 \%$ of frontal cortex samples 
of patients with $\mathrm{ASD}$, and increased $M e C P 2$ promotor methylation was particularly prominent in males with ASD compared to controls [30]. A recent study by LaddAcosta et al. [31] investigated over 485,000 CpG loci across functionally relevant genomic regions using the Infinium Human Methylation 450 Bead Chip and identified 4 differentially methylated regions located within PRRT1, TSPAN32, C11orf21, ZFP57 and SDHAP3 from different parts of the brain, which offers novel candidate genes for ASD. Genomic imprinting, which arises from parent-specific methylation patterns, has been thought to play a role in ASD because of findings of parent-of-origin effect on some chromosomal regions, such as 7q. It has been proposed that ASD is caused by an overbalance of paternally expressed genes. Schneider and colleagues analyzed the methylation and expression patterns of the MEST, COPG2, and TSGA14 on 7q in the brain cortex of humans and a variety of primates [32]. Compared to other primates, expression of the COPG2 gene was down regulated in human cortex because of methylation. The authors suggest that down regulation of COPG2 in humans may partially account for the emergence of the more advanced "social brain". ASD is considered a disorder of the "social brain", therefore genetic and epigenetic variants in genes such as COPG2 may play a role in susceptibility to autism and other pediatric mental disorders [33].

Stefanowicz et al. studied DNA methylation in airway epithelial cells (AECs) and peripheral blood mononuclear cells (PBMCs) from atopic, atopic asthmatic, non-atopic asthmatic children and healthy controls [34]. To measure genomic methylation they used Illumina Golden Gate Methylation Cancer Panel 1, which includes 1505 CpG loci across 807 genes. Gene expression was performed using RT-PCR. Of the differentially methylated CpG sites in airway epithelial cells, 13 were specific to healthy controls, 8 were found only in atopics, and 6 were unique to asthmatics. Genomes from asthmatics differed from atopics at 8 sites that included $\mathrm{CpG}$ sites in genes that encode transcription factor STAT5A and zinc transport protein CRIP1. The authors found that STAT5A gene expression is decreased and CRIP1 expression is elevated in airway epithelial cells from asthmatics compared to healthy and atopic subjects. In PBMCs no differences in the methylation status of these genes were found, so that PBMCs did not serve as alternatives to studies of airway epithelial cells. This study highlights the importance of studying the right tissue, when identifying epigenomic changes in disease. A recent study by Yang et al. [35] compared the blood DNA methylation levels at $\sim 480,000 \mathrm{CpG}$ sites between 97 controls and 97 asthmatic patients and identified 81 differentially methylated CpG sites. Validated CpG sites are located at RUNX3, IL4, and catalase. CpG sites associated with serum IgE among asthmatics were also discovered. Studies of DNA methylation are often coupled with gene expression studies and genetic variation studies, as DNA methylation can regulates gene expression [36] and SNPs also modifies DNA methylation [37, 38]. Acevedo and colleagues studied the association of childhood asthma with CpG sites polymorphisms, regional DNA methylation and gene expression at the GSDMB/ORMDL3 locus, which is located at $17 \mathrm{q} 21$, a novel asthma-susceptibility locus found in ethically diverse populations [39]. As expected, the $\mathrm{CpG}$ sites polymorphisms that either create or remove $\mathrm{CpG}$ sites alters DNA methylation and are associated with asthma. They are also associated with mRNA expression changes in ORMDL3. In addition, the methylation levels at ORMDL3 promoter in asthmatic children is also significantly higher compared to controls, and is correlated with ORMDL3 expression in blood leukocytes. Interestingly, SNPs and CpG methylation are independently associated with ORMDL3 expression, suggesting two independent mechanisms regulating gene expression.

\section{Gene expression profiles}

Exploring gene expression profiles of normal and diseased tissues has long played a major role in understanding the pathophysiology of disease. Originally such studies were primarily conducted using expression microarrays. Use of microarrays is now typically coupled with studies using high throughput technologies such as RNA-seq [40-47]. These techniques have enabled the generation of lists of top putative candidates of differentially expressed genes between different groups in diseases of interest. Studies of gene expression generate information about alternative splicing of RNA transcripts, the role of non-coding genomic elements (ncRNAs, ncDNAs, and microRNAs), and epigenetic changes in the genome [48-51].

Hundreds of susceptibility loci and candidate genes for ASD have been identified [52, 53]. Despite these findings, only a handful of genetic variants have been consistently found to be associated with the risk of ASD across different population. Whole-exome sequencing has identified biallelic mutations in several genes previously associated with ASD (AMT, PEX7, SYNE1, APS13B, $P A H$, and POMGNT1) and demonstrated the importance of partial loss of gene function in this disorder [54]. Splicing mutations may also play a role in susceptibility to ASD [55-57]. Yan and colleagues [58] found that neurexin 1alpha structural variants, including a splicing mutation, could distinguish patients with ASD from healthy controls. Genetic variation in ion channel genes, such as CACNA1C and CADPS2, may modulate 
the risk of ASD [59-61]. A genome-wide scan of micro RNAs (miRNAs) in cell lines established from patients with ASD compared to normal controls suggested that miRNAs dysregulated several coding and non-coding genes, including HEY1, SOX9, miR-486 and miR-181b, and increased the risk of ASD [62]. All of these genes are involved in nervous system development and function. One recent study of postmortem human brains reported that noncoding antisense RNA transcripts are generated at approximately $40 \%$ of loci previously implicated in ASD. The antisense RNA corresponding to synaptic ras GTPase-activating protein 1 (SYNGAP1) was differentially expressed in brain regions from patients with ASD compared to normal controls [63].

Microarray and RNA-sequencing experiments have been performed on nasal epithelial cells, bronchial epithelial cells, small airways, and blood cells from asthmatics and controls [64-68]. Significant differential expression in 70 genes in nasal cells, including IL13, IL5, periostin (POSTN), calcium-activated chloride channel regulator 1 (CLCA1), and serpin peptidase inhibitor, clade B (SERPINB2), was found to be linked to airway remodeling, production of mucus, and shifting of the immune response toward the Th2 phenotype thus enhancing asthma exacerbation [67,68]. Genome-wide association studies have identified CDHR3 (cadherin-related family member 3) gene as a novel susceptibility locus for early life childhood asthma with severe exacerbations [69]. This gene is highly expressed in airway epithelium and encodes a calciumdependent cell adhesion protein. Custom microarrays designed to measure expression of genes thought to play a role in the pathogenesis of asthma have proved useful in establishing the biological relevance of these genes [70]. $K L F 3 A$ was identified as a susceptibility gene for childhood asthma by gene expression arrays in nasal cells and further studies found that genetic variation in $K L F 3 A$ is associated with asthma.

\section{Genetic regulatory networks}

Information on co-regulators and co-expression of genes in normal and disease states has increased interest in genetic regulatory networks. The generation of genetic variation/gene expression profiles by either array or sequencing platforms affords the opportunity to define connectivity maps. This permits assignment of genetic variants associated with pediatric disorders to specific biochemical pathways and regulatory networks [71-73]. These technologies have been applied to ASD, cancer and other diseases and have uncovered mechanisms of action of disease specific target genes. Knowledge of genomic changes can be used to identify the biochemical pathways and regulatory networks that are affected and identify potential targets for drug therapy. Molecular classification of a patient's disease should improve choices of therapy at diagnosis, given a particular molecular subtype, and lead to development of new therapies for subtypes with a poor prognosis.

\section{Conclusions}

Besides identifying disease specific biomarkers, one future direction is to integrate the studies in genome architecture, epigenomics, and gene expression to understand the underlining mechanisms of pediatric diseases. Cutting-edge genome/epigenome-editing tools have the potential to correct disease-related variations and to develop novel therapies. We have discussed genomic mutations and epigenetic modifications in pediatric asthma and ASD. Many of these advances represent progress beyond the era of functional genomics, which focused on measurements of gene expression. The products of post-transcriptional and genomic variations, including non-coding genetic elements and copy number variations are drivers of disease initiation and progression. Unveiling changes in the genome that underlie disease identify new biomarkers that should prove to be associated with different outcomes of treatment and provide targets for development of new therapies. The continuing development of robust methods for NGS (next generation sequencing) and other technologies will continue to improve our ability to identify causes of disease in an individual patient and to use this information to personalize therapy.

\section{Authors' contributions}

$\mathrm{PL}$ and $\mathrm{DB}$ are experts in autism; $\mathrm{HJ}$ is an expert in asthma. These authors searched the literature, analyzed and interpreted data in their fields of specialization and wrote the original separate sections on autism and asthma, respectively. $\mathrm{SO}$ and $\mathrm{JH}$ are experts in informatics, conceived of the review, integrated and edited the specialty sections, and prepared the final draft. All authors were involved in editing the revised version of the manuscript. All authors read and approved the final manuscript.

\section{Author details \\ ${ }^{1}$ Department of Computer Science and Statistics, Jeju National University, Jeju Ciy, Jeju Do, South Korea. ${ }^{2}$ Division of Asthma Research, Department of Pedi- atrics, Cincinnati Children's Hospital Medical Center, Cincinnati, OH 45229, USA. ${ }^{3}$ Division of Psychiatry, Department of Pediatrics, Cincinnati Children's Hospital Medical Center, Cincinnati, OH 45229, USA. ${ }^{4}$ Division of Biostatistics and Epidemiology, Department of Pediatrics, Cincinnati Children's Hospital Medical Center, Cincinnati, OH, USA. ${ }^{5}$ Division of Biomedical Informatics, Department of Pediatrics, Cincinnati Children's Hospital Medical Center, Cincinnati, OH 45229, USA.}

\section{Acknowledgements}

We are grateful to Dr. Seongho Song and Dr. Joo-Seop Park for fruitful discussions and comments.

\section{Competing interests}

The authors declare that they have no competing interests.

Received: 9 September 2015 Accepted: 29 November 2015 Published online: 14 December 2015 


\section{References}

1. Baxter AJ, Brugha TS, Erskine HE, Scheurer RW, Vos T, Scott JG (2015) The epidemiology and global burden of autism spectrum disorders. Psychol Med 45:601-613

2. Loftus PA, Wise SK. Epidemiology and economic burden of asthma. Int Forum Allergy Rhinol. 2015; Suppl 1:S7-10

3. Krumm N, Sudmant PH, Ko A, O'Roak BJ, Malig M, Coe BP et al (2012) Copy number variation detection and genotyping from exome sequence data. Genome Res 22:1525-1532

4. Devlin B, Scherer SW (2012) Genetic architecture in autism spectrum disorder. Curr Opin Genet Dev 22:229-237

5. Sebat J, Lakshmi B, Malhotra D, Troge J, Lese-Martin C, Walsh T et al (2007) Strong association of de novo copy number mutations with autism. Science 316:445-449

6. Celestino-Soper PB, Violante S, Crawford EL, Luo R, Lionel AC, Delaby E et al (2012) A common X-linked inborn error of carnitine biosynthesis may be a risk factor for nondysmorphic autism. Proc Natl Acad Sci USA 109:7974-7981

7. O'Roak BJ, Vives L, Fu W, Egertson JD, Stanaway IB, Phelps IG et al (2012) Multiplex targeted sequencing identifies recurrently mutated genes in autism spectrum disorders. Science 338:1619-1622

8. Yu TW, Chahrour MH, Coulter ME, Jiralerspong S, Okamura-Ikeda K, Ataman B et al (2013) Using whole-exome sequencing to identify inherited causes of autism. Neuron 77:259-273

9. Vaishnavi V, Manikandan M, Tiwary BK, Munirajan AK (2013) Insights on the functional impact of microRNAs present in autism-associated copy number variants. PLoS One 8:e56781

10. Kerin T, Ramanathan A, Rivas K, Grepo N, Coetzee GA, Campbell DB (2012) A noncoding RNA antisense to moesin at 5p14.1 in autism. Sci Transl Med 4:128ra40

11. Persico AM, Napolioni V (2013) Autism genetics. Behav Brain Res 251:95-112

12. Rogers AJ, Chu JH, Darvishi K, lonita-Laza I, Lehmann H et al (2013) Copy number variation prevalence in known asthma genes and their impact on asthma susceptibility. Clin Exp Allergy 43:455-462

13. Shugay M, de Mendíbil IO, Vizmanos JL, Novo FJ (2013) Oncofuse: a computational framework for the prediction of the oncogenic potential of gene fusions. Bioinformatics 29:2539-2546

14. Holt R, Sykes NH, Conceição IC, Cazier JB, Anney RJ, Oliveira G et al (2012) CNVs leading to fusion transcripts in individuals with autism spectrum disorder. Eur J Hum Genet 20:1141-1147

15. Ceroni F, Sagar A, Simpson NH, Gawthrope AJ, Newbury DF, Pinto D et al (2014) A deletion involving CD38 and BST1 results in a fusion transcript in a patient with autism and asthma. Autism Res 7:254-263

16. Marques-Rocha JL, Samblas M, Milagro Fl, Bressan J, Martínez JA, Marti A (2015) Noncoding RNAs, cytokines, and inflammation-related diseases. FASEB J. 29:3595-3611

17. Geaghan M, Cairns MJ (2015) MicroRNA and posttranscriptional dysregulation in psychiatry. Biol Psychiatry 78:231-239

18. Wilkinson B, Campbell DB (2013) Contribution of long noncoding RNAs to autism spectrum disorder risk. Int Rev Neurobiol 113:35-59

19. Ziats MN, Rennert OM (2013) Aberrant expression of long noncoding RNAs in autistic brain. J Mol Neurosci 49:589-593

20. Nunnari J, Suomalainen A (2012) Mitochondria: in sickness and in health. Cell 148:1145-1159

21. Flaquer A, Heinzmann A, Rospleszcz S, Mailaparambil B, Dietrich H, Strauch K, Grychtol R (2014) Association study of mitochondrial genetic polymorphisms in asthmatic children. Mitochondrion 14:49-53

22. Rossignol DA, Frye RE (2012) Mitochondrial dysfunction in autism spectrum disorders: a systematic review and meta-analysis. Mol Psychiatry. 17:290-314

23. Liyanage VR, Jarmasz JS, Murugeshan N, Del Bigio MR, Rastegar M, Davie JR (2014) DNA modifications: function and applications in normal and disease states. Biology (Basel) 3:670-723

24. Patil V, Ward RL, Hesson LB (2014) The evidence for functional non-CpG methylation in mammalian cells. Epigenetics 9:823-828

25. Nelson VR, Heaney JD, Tesar PJ, Davidson NO, Nadeau JH (2012) Transgenerational epigenetic effects of the Apobec1 cytidine deaminase deficiency on testicular germ cell tumor susceptibility and embryonic viability. Proc Natl Acad Sci USA 109:E2766-E2773
26. Kofink D, Boks MP, Timmers HT, Kas MJ (2013) Epigenetic dynamics in psychiatric disorders: environmental programming of neurodevelopmental processes. Neurosci Biobehav Rev 37:831-845

27. Guintivano J, Kaminsky ZA (2014) Role of epigenetic factors in the development of mental illness throughout life. Neurosci Res S0168-0102(14):00179-000185

28. St Pourcain B, Cents RA, Whitehouse AJ, Haworth CM, Davis OS, O'Reilly $\mathrm{PF}$ et al (2014) Common variation near $\mathrm{ROBO} 2$ is associated with expressive vocabulary in infancy. Nat Commun 5:4831

29. Jones JR, Skinner C, Friez MJ, Schwartz CE, Stevenson RE (2008) Hypothesis: dysregulation of methylation of brain-expressed genes on the X chromosome and autism spectrum disorders. Am J Med Genet A 146A:2213-2220

30. Nagarajan RP, Hogart AR, Gwye Y, Martin MR, LaSalle JM (2006) Reduced $\mathrm{MeCP} 2$ expression is frequent in autism frontal cortex and correlates with aberrant MECP2 promoter methylation. Epigenetics 1:e1-e11

31. Ladd-Acosta C, Hansen KD, Briem E, Fallin MD, Kaufmann WE, Feinberg AP (2014) Common DNA methylation alterations in multiple brain regions in autism. Mol Psychiatry 19:862-871

32. Schneider E, Mayer S, El Hajj N, Jensen LR, Kuss AW, Zischler H et al (2012) Methylation and expression analyses of the $7 \mathrm{q}$ autism susceptibility locus genes MEST, COPG2, and TSGA14 in human and anthropoid primate cortices. Cytogenet Genome Res 136:278-287

33. McGowan PO, Szyf M (2010) The epigenetics of social adversity in early life: implications for mental health outcomes. Neurobiol Dis 39:66-72

34. Stefanowicz D, Hackett TL, Garmaroudi FS, Günther OP, Neumann S, Sutanto EN et al (2012) DNA methylation profiles of airway epithelial cells and PBMCs from healthy, atopic and asthmatic children. PLoS One 7:e44213

35. Yang IV, Pedersen BS, Liu A, O'Connor GT, Teach SJ, Kattan M et al (2015) DNA methylation and childhood asthma in the inner city. J Allergy Clin Immunol. 136:69-80

36. Jones PA (2012) Functions of DNA methylation: islands, start sites, gene bodies and beyond. Nat Rev Genet 13:484-492

37. van Eijk KR, de Jong S, Boks MP, Langeveld T, Colas F, Veldink JH et al (2012) Genetic analysis of DNA methylation and gene expression levels in whole blood of healthy human subjects. BMC Genom 13:636

38. Wagner JR, Busche S, Ge B, Kwan T, Pastinen T, Blanchette M (2014) The relationship between DNA methylation, genetic and expression interindividual variation in untransformed human fibroblasts. Genome Biol 15:R37

39. Acevedo N, Reinius LE, Greco D, Gref A, Orsmark-Pietras C, Persson $H$ et al (2015) Risk of childhood asthma is associated with CpG-site polymorphisms, regional DNA methylation and mRNA levels at the GSDMB/ ORMDL3 locus. Hum Mol Genet 24:875-890

40. Allison DB, Cui X, Page GP, Sabripour M (2006) Microarray data analysis: from disarray to consolidation and consensus. Nat Rev Genet 7:55-65

41. Caron H, van Schaik B, van der Mee M, Baas F, Riggins G, van Sluis P et al (2001) The human transcriptome map: clustering of highly expressed genes in chromosomal domains. Science 291:1289-1292

42. Nueda MJ, Carbonell J, Medina I, Dopazo J, Conesa A (2010) Serial Expression Analysis: a web tool for the analysis of serial gene expression data. Nucleic Acids Res 38:W239-W245

43. Ramaswamy S, Golub TR (2002) DNA microarrays in clinical oncology. J Clin Oncol 20:1932-1941

44. Young RA (2000) Biomedical discovery with DNA arrays. Cell 102:9-15

45. Hitzemann R, Bottomly D, Darakjian P, Walter N, lancu O, Searles R et al (2013) Genes, behavior and next-generation RNA sequencing. Genes Brain Behav 12:1-12

46. Malone JH, Oliver B (2011) Microarrays, deep sequencing and the true measure of the transcriptome. BMC Biol 9:34

47. Sims D, Sudbery I, llott NE, Heger A, Ponting CP (2014) Sequencing depth and coverage: key considerations in genomic analyses. Nat Rev Genet 15:121-132

48. Grech G, Pollacco J, Portelli M, Sacco K, Baldacchino S, Grixti J et al (2014) Expression of different functional isoforms in haematopoiesis. Int J Hematol 99:4-11

49. Sultan M, Schulz MH, Richard H, Magen A, Klingenhoff A (2008) Scherf $M$, et al. A global view of gene activity and alternative splicing by deep sequencing of the human transcriptome. Science 32:956-960 
50. Stunnenberg HG, Hubner NC (2014) Genomics meets proteomics: identifying the culprits in disease. Hum Genet 133:689-700

51. Girardot M, Cavaillé J, Feil R (2012) Small regulatory RNAs controlled by genomic imprinting and their contribution to human disease. Epigenetics 7:1341-1348

52. Vardarajan BN, Eran A, Jung JY, Kunkel LM, Wall DP (2013) Haplotype structure enables prioritization of common markers and candidate genes in autism spectrum disorder. Transl Psychiatry. 3:e262

53. Sanders SJ, He X, Willsey AJ, Ercan-Sencicek AG, Samocha KE, Cicek AE et al (2015) Insights into autism spectrum disorder genomic architecture and biology from 71 risk loci. Neuron 87:1215-1233

54. Yu TW, Chahrour MH, Coulter ME, Jiralerspong S, Okamura-Ikeda K (2013) Ataman B,et al. Using whole-exome sequencing to identify inherited causes of autism. Neuron 77:259-273

55. Talebizadeh Z, Aldenderfer R, Chen XW (2014) A proof-of-concept study: exon-level expression profiling and alternative splicing in autism using lymphoblastoid cell lines. Psychiatr Genet 24:1-9

56. Voineagu I, Wang X, Johnston P, Lowe JK, Tian Y, Horvath S et al (2011) Transcriptomic analysis of autistic brain reveals convergent molecular pathology. Nature 474:3804

57. Miyauchi S, Voineagu I (2013) Autism susceptibility genes and the transcriptional landscape of the human brain. Int Rev Neurobiol 113:303-318

58. Yan J, Noltner K, Feng J, Li W, Schroer R, Skinner C et al (2008) Neurexin 1alpha structural variants associated with autism. Neurosci Lett 438:368-370

59. Bhat S, Dao DT, Terrillion CE, Arad M, Smith RJ, Soldatov NM et al (2012) CACNA1C (Cav1.2) in the pathophysiology of psychiatric disease. Prog Neurobiol 99:1-14

60. Garcia-Junco-Clemente P, Chow DK, Tring E, Lazaro MT, Trachtenberg JT, Golshani P (2013) Overexpression of calcium-activated potassium channels underlies cortical dysfunction in a model of PTEN-associated autism. Proc Natl Acad Sci USA 110:18297-18302

61. Bonora E, Graziano C, Minopoli F, Bacchelli E, Magini P, Diquigiovanni C et al (2014) Maternally inherited genetic variants of CADPS2 are present in autism spectrum disorders and intellectual disability patients. EMBO Mol Med 6:795-809

62. Ghahramani Seno MM, Hu P, Gwadry FG, Pinto D, Marshall CR, Casallo G et al (2011) Gene and miRNA expression profiles in autism spectrum disorders. Brain Res 1380:85-97
63. Velmeshev D, Magistri M, Faghihi MA (2013) Expression of non-proteincoding antisense RNAs in genomic regions related to autism spectrum disorders. Mol Autism 4:32

64. Aoki T, Matsumoto Y, Hirata K, Ochiai K, Okada M, Ichikawa K et al (2009) Expression profiling of genes related to asthma exacerbations. Clin Exp Allergy 39:213-221

65. Guajardo JR, Schleifer KW, Daines MO, Ruddy RM, Aronow BJ, Wills-Karp M et al (2005) Altered gene expression profiles in nasal respiratory epithelium reflect stable versus acute childhood asthma. J Allergy Clin Immunol 115:243-251

66. Laprise C, Sladek R, Ponton A, Bernier MC, Hudson TJ, Laviolette M (2004) Functional classes of bronchial mucosa genes that are differentially expressed in asthma. BMC Genom 5:21

67. Poole A, Urbanek C, Eng C, Schageman J, Jacobson S, O'Connor BP et al (2014) Dissecting childhood asthma with nasal transcriptomics distinguishes subphenotypes of disease. J Allergy Clin Immunol. 133:670-678

68. Woodruff PG, Boushey HA, Dolganov GM, Barker CS, Yang YH, Donnelly S et al (2007) Genome-wide profiling identifies epithelial cell genes associated with asthma and with treatment response to corticosteroids. Proc Natl Acad Sci USA. 104:15858-15863

69. Bønnelykke K, Sleiman P, Nielsen K, Kreiner-Møller E, Mercader JM, Belgrave D et al (2014) A genome-wide association study identifies CDHR3 as a susceptibility locus for early childhood asthma with severe exacerbations. Nat Genet 46:51-55

70. Kovacic MB, Myers JM, Wang N, Martin $L$, Lindsey M, Ericksen MB et al (2011) Identification of KIF3A as a novel candidate gene for childhood asthma using RNA expression and population allelic frequencies differences. PLoS One 6:e23714

71. Civelek M, Lusis AJ (2014) Systems genetics approaches to understand complex traits. Nat Rev Genet 15:34-48

72. Kavanagh T, Mills JD, Kim WS, Halliday GM, Janitz M (2013) Pathway analysis of the human brain transcriptome in disease. J Mol Neurosci 51:28-36

73. Ben-David E, Shifman S (2012) Networks of neuronal genes affected by common and rare variants in autism spectrum disorders. PLoS Genet 8(3):e1002556

\section{Submit your manuscript to a SpringerOpen ${ }^{\circ}$ journal and benefit from:}

- Convenient online submission

- Rigorous peer review

- Immediate publication on acceptance

- Open access: articles freely available online

- High visibility within the field

- Retaining the copyright to your article

Submit your next manuscript at $>$ springeropen.com 